\title{
REVIEWS
}

\section{Perceptions of Hospital-at-Home Among Stakeholders: a Meta-synthesis}

\author{
Crystal Min Siu Chua, BSc (Hons) ${ }^{7}$ (D) , Stephanie Qianwen Ko, MBBS, MMed, MPH ${ }^{5}$, \\ Yi Feng Lai, BSC (Pharm) (Hons), MPH, MPSS, FISQua ${ }^{2,3,4,6}{ }_{(\mathbb{D})}$, Yee Wei Lim, MBBS, PhD ${ }^{7,8}$, \\ and Shefaly Shorey, $P h D, R N, R M^{7}$ iD
}

\begin{abstract}
${ }^{1}$ Alice Lee Centre for Nursing Studies, Yong Loo Lin School of Medicine, National University of Singapore, Singapore, Singapore; ${ }^{2}$ Dept of Pharmacy, Alexandra Hospital, National University Health System, Singapore, Singapore; ${ }^{3}$ Dept of Pharmacy, Faculty of Science, National University of Singapore, Singapore, Singapore; ${ }^{4}$ School of Public Health, University of Illinois at Chicago, Chicago, USA; ${ }^{5}$ Advanced Internal Medicine, Department of Medicine, National University Hospital, Singapore, Singapore; ${ }^{6} \mathrm{MOH}$ Office for Healthcare Transformation, Singapore, Singapore; ${ }^{7}$ Medical Affairs - Research, Innovation \& Enterprise, Alexandra Hospital, National University Health System, Singapore, Singapore; ${ }^{8}$ Yong Loo Lin School of Medicine, Department of Medicine, National University of Singapore, Singapore, Singapore.
\end{abstract}

BACKGROUND: Hospital-at-home $(\mathrm{HaH})$ provides acute healthcare in patients' homes as an alternative to traditional hospital inpatient care. $\mathrm{HaH}$ has been shown to improve clinical outcomes, increase patient satisfaction, and reduce hospitalization costs. Despite its effectiveness, the uptake of $\mathrm{HaH}$ remains slow and little is known about factors that impact the quality and transferability of $\mathrm{HaH}$. This review aimed to qualitatively synthesize existing literature to examine the perspectives of stakeholders to identify areas of improvement in this model of care.

METHODOLOGY: Six electronic databases (Cumulative Index of Nursing and Allied Health Literature, PubMed, Embase, PsychINFO, Scopus, and Mednar) were searched from inception date until 3 February 2021. The included studies were assessed for quality using the Critical Appraisal Skills Program tool. This review was registered on the International Prospective Register of Systematic Reviews. The meta-synthesis was completed according to Sandelowski and Barroso's guidelines.

RESULTS: Sixteen articles met the inclusion criteria. The overarching synthesized theme was "the intricacies of developing $\mathrm{HaH}$," and the four main themes were (1) factors influencing patient selection, (2) advantages of $\mathrm{HaH}$, (3) challenges of $\mathrm{HaH}$, and (4) enablers for $\mathrm{HaH}$ development. CONCLUSION: Overall, high levels of satisfaction were expressed by various stakeholders. Continuity of care remains an important factor for patient-centeredness in $\mathrm{HaH}$. Caregivers should be involved in the decisionmaking process and supported throughout the $\mathrm{HaH}$ duration to prevent caregiver burnout. Collaboration and coordination among healthcare professionals are vital and can be strengthened through training and technological advancements of remote patient monitoring. Institutional and organizational support for stakeholders may make $\mathrm{HaH}$ a viable solution to modern healthcare challenges.

KEY WORDS: hospital-at-home; healthcare professionals; healthcare administrators; patients; caregivers; perceptions; experience.

Received March 8, 2021

Accepted July 21, 2021

Published online August 6, 2021
J Gen Intern Med 37(3):637-50

DOI: $10.1007 / \mathrm{s} 11606-021-07065-0$

(C) Society of General Internal Medicine 2021

\section{INTRODUCTION}

Hospital-at-home $(\mathrm{HaH})$ provides acute healthcare in a patient's home as an alternative to traditional hospital inpatient care. This can be either a complete substitution for hospital care (admission avoidance) or a shorter hospital stay (early discharge $)^{1}$. This care model remains a viable solution to the increasing global need for acute care hospital beds, rising healthcare costs, and aging population ${ }^{2,3}$. While $\mathrm{HaH}$ is not novel, the emergence of the coronavirus disease 2019 (COVID-19) has brought new urgency to this mandate as the world grapples with the accelerating need for hospital beds and increased risk of nosocomial infections ${ }^{4}$. Studies have shown that $\mathrm{HaH}$ is a safe and effective alternative for COVID-19 patients with mild symptoms, which can reduce pressure on healthcare in the hospital ${ }^{5,6}$.

The impacts of $\mathrm{HaH}$ on readmission risk, health-related quality of life, and patient satisfaction ${ }^{7,8}$ have been well described in quantitative studies. A 2018 Cochrane review of $\mathrm{HaH}$ trials reported that $\mathrm{HaH}$ made little to no difference in mortality rate, decreased risk of hospital readmission in chronic obstructive pulmonary disease (COPD) patients, and slightly improved patient satisfaction ${ }^{9}$. The cost of $\mathrm{HaH}$ compared to traditional setting is much lower and can be cheaper by up to $38 \%{ }^{2,10}$. Despite its proposed benefits, HaH's impacts are not consistent. There is evidence that the risk of readmission may be higher for $\mathrm{HaH}$ when patients present with multiple medical conditions $^{9}$, and cost savings vary depending on the HaH's financing mechanism (e.g., fee-for-service versus bundle payment) ${ }^{11}$. Additionally, selecting appropriate patients for $\mathrm{HaH}$ remains a challenge. Most selection criteria are based on diagnostic and clinical criteria, with little consideration of how patient and environmental factors contribute to $\mathrm{HaH}^{12}$. 
Studies have also reported evidence of clinicians' frustrations from miscommunication within the interdisciplinary teams and difficulties with remote monitoring ${ }^{12,13}$. These challenges may contribute to the differential $\mathrm{HaH}$ outcomes that would not have been detected in quantitative research alone. Hence, there is a need to better understand and identify barriers (e.g., patient-centeredness and experience with delivering and receiving $\mathrm{HaH}$ care) for effective implementation.

In this review, we synthesized findings from qualitative studies examining the perceptions of stakeholders (patients, caregivers, healthcare professionals, and healthcare administrators) on their experiences with $\mathrm{HaH}$. To our knowledge, this is the first review which synthesizes the experiences and perspectives of stakeholders on $\mathrm{HaH}$. Our aim was to gain a comprehensive understanding of the opportunities, barriers, and facilitators of $\mathrm{HaH}$. The research questions were as follows: (1) what were stakeholders' perspectives and experiences with $\mathrm{HaH}$ ? and (2) what were perceived to be enablers of $\mathrm{HaH}$ ?

\section{METHODS}

\section{Aim}

This qualitative systematic review aimed to identify and synthesize available evidence of stakeholder perceptions of $\mathrm{HaH}$. We applied meta-summary followed by meta-synthesis using Sandelowski and Barroso's guideline ${ }^{14}$ to the included studies.

\section{Search Strategy}

This review was conducted based on Preferred Reporting Items for Systematic Reviews and Meta-Analysis (PRISMA) ${ }^{15}$, and the PRISMA checklist is reported in Supplementary Table 3. A three-step approach was adopted: (1) systematic search of various electronic databases, (2) manual search of journal references, and (3) discussion with qualitative content experts. An initial search was conducted on PubMed. Keywords and index terms, Boolean, and truncation symbols were used. Subsequently, the search strategy was adapted to six electronic databases: Cumulative Index to Nursing and Allied Health Literature (CINAHL), PubMed, Embase, PsychINFO, Scopus, and Mednar (gray literature) from inception until 3 February 2021. A literature search expert from the university was consulted to ensure a comprehensive search strategy ${ }^{16}$. The complete search strategy is available in Supplementary Table 1. Duplicated references were removed using Endnote X9. Titles and abstracts, followed by full-text records, were screened by two reviewers (CC and SS). A manual search of the included studies' reference list was performed. Any discrepancies were resolved by consensus. This review was registered on the Prospective Register of Systematic Reviews (CRD42020223502).

\section{Inclusion and Exclusion Criteria}

Articles that were not written in English were translated using Google Translate. The inclusion criteria were as follows: (a) studies exploring the perceptions and/or experiences of an adult population as patients, caregivers, healthcare professionals, and healthcare administrators; (b) studies examining treatments via $\mathrm{HaH}$, defined as the provision of hospitallevel care in a patient's home as an alternative for acute hospital care; and (c) studies of any type of qualitative study design or mixed-methods, with a qualitative component where the qualitative findings can be extracted. This included studies that obtained data from first-hand observation from researchers, interviews, focus groups, participants, and recordings made in natural setting. Studies were excluded if the population who received $\mathrm{HaH}$ care were children or adolescents.

\section{Quality Appraisal}

The two reviewers (CC and SS) conducted the quality assessment of the included studies using the Critical Appraisal Skills Program (CASP) tool ${ }^{17}$. This 10 -item questionnaire comprehensively appraised various qualitative research and had been used in similar systematic reviews ${ }^{18}$. CASP evaluated the included studies on their (1) clarity and appropriateness of their aims, (2) methodology, (3) study design, (4) sampling method, (5) data collection, (6) reflexivity of the research, (7) ethical considerations, (8) data analysis, (9) rigor of findings, and (10) significance of the study. Responses from the 10-item questionnaires were "Yes," "Can't Tell," or "No" with ratings of "3 points," "2 points," or "1 point," respectively. The CASP score ranged from 26 to 30 points, with a total average score of 27.8 (Supplementary Table 2). The purpose of CASP was not to assign a meaning to the score for each study but to increase the rigor of the synthesis ${ }^{18,19}$. Thus, none of the studies was excluded based on their score, and all studies were equally regarded in our analysis.

\section{Data Extraction}

Data extraction (Table 1) from the included studies was conducted independently by the two reviewers (CC and SS), and extracted data were compared to ensure consistency. The extracted data were as follows: study details (e.g., author, year of publication, title of study, and country), study aims (e.g., aims, study design, methodology), sample (e.g., sample size, study inclusion criteria, participants' characteristics), study method (data collection methods, data analysis strategy), and the results (e.g., themes and/or subthemes).

\section{Data Synthesis}

To conduct data synthesis, Sandelowski and Barroso's approach was employed ${ }^{14}$. Firstly, findings of the included studies were extracted, separated, grouped, and abstracted into statements through a process called meta-summarizing. The statements were then categorized into main themes and 
Table 1 Characteristics of Included Studies

\begin{tabular}{ll}
\hline \hline No. & Study \\
\hline 1 & Brody et al., 2019 \\
& Starting Up a Hospital at \\
& Home Program: \\
& Facilitators and Barriers \\
& to Implementation
\end{tabular}

to Implementation
There's no place like home: a prospective evaluation of chemotherapy in the home

Cafazzo, Leonard, Easty, Rossos, \& Chan, 2009 The user-centered approach in the development of a complex hospital-at home intervention
USA

Spain

Wensley, \& Sánchez-

Polo, 2010

An Application of the

Hospital-in-the-Home

Unlearning Context
5 Cœugnet et al., 2016

Time pressure and regulations on hospital-in-the-home nurses: An on-the-road study
Australia

To determine patient satisfaction with treatment of $\mathrm{HaH}$

\begin{tabular}{lllll}
\hline Country & Aim & Characteristic & Methodology & Results \\
\hline USA & To examine & Sample: 2 focus & Study design: & Six themes \\
& facilitators and & group (10 healthcare & Qualitative study; & Health systems and \\
barriers to & professionals and 9 & Semi structured & policies (4 themes) \\
implementation of & healthcare & interview & - Policy and regulatory \\
& HaH-Plus over its & administrative & Methodology: Not & - Billing and payment \\
first year of operation & respectively) and 7 & specified & - Screening, \\
to provide others the & individual interviews & Analysis: Inductive & identifying, recruiting \\
& opportunity to plan & with other healthcare & thematic analysis & patients \\
effectively for opera- & partners & & - Implementing the \\
tionalization & HaH setting: Early & & electronic health \\
& discharge and & & records \\
& 30-day post-acute & & Partnerships (2 themes) \\
& transitional care for & & - Early development of \\
& patients with various & & partnership \\
& diagnosis (e.g., asth- & & - Building \\
& ma exacerbation) & & coordination, \\
& Inclusion criteria: & & communication and \\
& Physicians, nurses, & & protocolion exchange
\end{tabular}

Study design:

Qualitative study;

Semi structured

interview

Methodology:

Prospective

Analysis: Thematic

analysis

Inclusion criteria:

Patients receiving

home chemotherapy

who lived within a

$20 \mathrm{~km}$ radius from

the hospital

To discuss the development of a patient monitoring system for patients undergoing nocturnal home hemodialysis in $\mathrm{HaH}$

Sample: 7 nocturna home hemodialysis patients compared

with 6 conventional hemodialysis

patients, and 7 predialysis patients

HaH setting: Early discharge to nocturnal home hemodialysis

Inclusion criteria:

Patients with renal

diseases undergoing nocturnal home hemodialysis, conventional hemodialysis or pre-dialysis

Sample: 4 nurses, 2 medical doctor, 1

doctor manager perceptions of key agents with respect to the creation and management of unlearning

France

To investigate factors that elicited time pressure in nurses and examine the deleterious consequences of time pressure
HaH setting: Home Hospital Unit designed for stable patients needing intravenous drugs

Inclusion criteria:

Nurses, medical

doctors and docto manager from the Home Hospital Unit

Sample: 4 nurses

HaH setting: $\mathrm{HaH}$ for palliative, punctual and patients needing rehabilitation
Four themes

- Eliminates traveling problems

- Reduces anxiety and trauma, more relaxed/comfortable - Does not burden carer - Enable patients to care for family

Study design:

Qualitative study;

Semi structured

interview

Methodology:

Ethnographic

Analysis: Thematic analysis

Study design:

Exploratory

qualitative study; both

semi-structured and open- ended inter-

views

Methodology: Not specified

Analysis: Content analysis

Five themes

- Physical

obtrusiveness reducing

adherence

- Fear for potential

blood loss during home

hemodialysis

- Need for immediate response during emergencies

- Caregivers seen as surrogates for nursing care

- "Big Brother" effect from remote monitoring and caregiver

Three categories - Examination of perceptual lenses - Facilitating the changing of individual habits

- Consolidation of emergent understanding
Study design:

Qualitative study; semi-structured interviews

Methodology: Not specified
Three themes

- Time constraints

- Challenges

- Uncertainties encountered during professional activities 
Table 1. (continued)

\begin{tabular}{ll}
\hline \hline No. & Study \\
\hline & \\
$6 \quad$ & $\begin{array}{l}\text { Dismore et al., } 2016 \\
\text { What are the positive } \\
\text { drivers and potential } \\
\text { barriers to } \\
\text { implementation of } \\
\text { hospital at home selected } \\
\text { by low-risk DECAF score } \\
\text { in the UK }\end{array}$
\end{tabular}

Jester, 2003

Early discharge to hospital at home: should it be a matter of choice?
Khalifeh, Murgatroyd, Freeman, Johnson, \& Killaspy, 2009

Home Treatment as an Alternative to Hospital Admission for Mothers in a Mental Health Crisis: A Qualitative Study

$\begin{array}{ll}\text { UK } & \begin{array}{l}\text { To uncover the } \\ \text { drivers and barriers } \\ \text { toward } \mathrm{H} @ \mathrm{H}\end{array}\end{array}$

UK

To discuss the patient and family choice on $\mathrm{HaH}$ early discharge and how a simple screening tool may determine the suitability $\mathrm{HaH}$ for orthopedic patients and their informal carers

UK

To explore the experiences, treatment preferences, and needs of mothers of dependent children who were treated at home as an alternative to hospital admission for an acute severe mental health crisis.

$\begin{array}{lll}\text { Characteristic } & \text { Methodology } & \text { Results } \\ \begin{array}{l}\text { Inclusion criteria: } \\ \text { Nurses working full } \\ \text { time on the same }\end{array} & \begin{array}{l}\text { Analysis: Thematic } \\ \text { analysis }\end{array} & \end{array}$

time on the same

$\mathrm{HaH}$ team

Participation of genera

practitioners in the

management of their

"hospital at home"

patients

focus group

To identify the incentives and obstacles to the participation of general practitioners HaH setting: Not in $\mathrm{HaH}$

specified
Sample: 89

participants; 44

patients, 15 carers,

15 physicians, 11 respiratory specialist nurses, 4 managers

HaH setting: For

patients with

Chronic Obstructive

Pulmonary Disease

(COPD) exacerba-

tion of low-risk

dyspnoea,

Eosinopenia,

consolidation, acid-

aemia and atrial fi-

brillation scores

Inclusion criteria:

Patients in $\mathrm{HaH}$ and

those receiving usual

care, respiratory

specialist nurses and consultants, key acute physicians and managers of $\mathrm{HaH}$

Sample: 21 carers of

$\mathrm{HaH}$ patients

HaH setting: Early

discharge for

patients with primary

hip and knee

replacement who are

not living alone

Inclusion criteria:

Primary carers of

patients with chief

diagnosis of

osteoarthritis of hip

or knee joints whom

require primary total

hip or knee

replacement

Sample: 18 patients

who are mothers and

5 of their children

HaH setting: Early

discharge to home

treatment for

mothers with major

depression, bipolar

disorder or

schizophrenia

Inclusion criteria:

Mothers with

responsibility for a

child younger than

18 years, and of

stable mental state at

the time of

interview. Children

from age 12-18 with

mothers participating

in $\mathrm{HaH}$.

Sample: 12 general

practitioners in one

Study design:

Qualitative study; semi-structured interviews

Methodology:

Inductive-deductive

Analysis:

Thematic-construct

analysis

Study design: Quasiexperimental design; semi-structured interviews

Methodology: Not specified

Analysis: Thematic analysis

Study design:

Qualitative

exploratory study;

semi-structured interviews

Methodology: Not

specified

Analysis: Inductive

thematic analysis
Study design:

Ground theory study; semi-structured interviews

Methodology:

Ground Theory

Three themes

- Positive drivers of

$\mathrm{HaH}$

- Confidence in the

continuity of $\mathrm{HaH}$ care

- Potential barriers and negative influence for $\mathrm{HaH}$ care pathway

Three themes:

- Patient and carer choice

- Locus of control

- Coping abilities

Five themes:

- Difficulty in meeting children's physical needs and maintaining normal boundaries

- Lack of emotional connectedness with children

- Exposing children to distressing symptoms or behaviors

- Incorporating the children in their symptoms

- Burdening the child with caregiving responsibilities

Three themes:

- Good knowledge of directions and locations of $\mathrm{HaH}$ but difficulties in entry request 
Table 1. (continued)

\begin{tabular}{ll}
\hline \hline No. & Study \\
\hline & \\
$10 \quad \begin{array}{l}\text { Mäkelä et al., 2020 } \\
\text { The work of older people } \\
\text { and their informal } \\
\text { caregivers in managing an } \\
\text { acute health event in a } \\
\text { hospital at home or } \\
\text { hospital inpatient setting }\end{array}$
\end{tabular}

UK

$\begin{array}{ll}\text { Country } & \text { Aim } \\ & \\ & \\ \text { UK } & \begin{array}{l}\text { To explore the work } \\ \text { of older people and } \\ \text { caregivers at the time } \\ \text { of an acute health } \\ \text { event, the interface } \\ \text { with professionals in } \\ \text { HAH }\end{array}\end{array}$

11

dessinot, Marquesta

The experience of patients and family caregivers during hospital-at-home in

France

Sims, Rink, Walker, \&

Pickard, 1997

The introduction of a

hospital at home service-

A staff perspective
13 Utens et al., 2013

Patient preference and satisfaction in

hospital-at-home and usual hospital care for COPD exacerbations:

Results of a randomised controlled trial

\begin{tabular}{lll} 
Characteristic & Methodology & Results \\
\hline $\begin{array}{l}\text { Inclusion criteria: } \\
\text { General practitioners }\end{array}$ & $\begin{array}{l}\text { Analysis: Ground } \\
\text { theory analysis }\end{array}$ & $\begin{array}{l}\text { - Difficulties in } \\
\text { identifying roles in }\end{array}$ \\
half of their & & HaH \\
medicine activities & & - Requiring support \\
from other clinicians
\end{tabular}

activities

Sample: 34 older

Netherlands To investigate patient Sample: $56 \mathrm{HaH}$

preference for

treatment place,

associated factors

and patient

satisfaction with a

community-based

hospital-at-home

scheme for COPD

exacerbations. patients $(15 \mathrm{HaH}$

patients, 19 hospital-

care patients) and 29

caregivers $(12 \mathrm{HaH}$,

17 hospital care)

HaH setting:

Geriatrician-led ad-

mission avoidance

for older patients

with various diagno-

sis

Inclusion criteria:

Older patients and

their caregivers.

Patients were either

living alone, with

caregiver or in

sheltered

accommodations.

Sample: 9 patients,

10 caregivers

HaH setting: $\mathrm{HaH}$

for patients with

various prognosis

such as cancer,

diabetes, or needing

post-fracture care

Inclusion criteria:

Patients who are

above 16 years old

with a primary

family caregiver

with $\mathrm{HaH}$ stay

longer than a week

Sample: $1^{\text {st }}$

interview: 6

orthopedic

consultants, 12

nurses, 7 healthcare

support workers, two

occupational

therapist, 1

physiotherapist

$2^{\text {nd }}$ interview: 7

healthcare workers, 9

nurses, 7 staff

members, 4

consultants

HaH setting: Early

discharge from the

orthopedic unit

Inclusion criteria:

Stakeholders of the

$\mathrm{HaH}$

patients vs 49

hospital patients

HaH setting: Early

discharge for COPD

patients and

additional 3 months

post-follow up

Inclusion criteria:

Patients age $\geq 40$

who were diagnosed

with COPD who are
Study design:

Qualitative study;

semi-structured inter-

views

Analysis: qualitative

analysis with

normalization process

theory

Study design:

Ground theory study;

semi-structured inter-

views

Methodology:

Inductive ground

theory

Analysis: Ground

theory analysis

Results

Patients and caregivers undertake

responsibilities in

managing health, and

work toward

longer-term strategies.

Personal, relational and environmental factors determine ability to manage care at home

Four themes:

- Participation to the decision of transfer to $\mathrm{HAH}$ and motivations

- Advantages and barriers of $\mathrm{HaH}$

- Impact on various

- Relationship between caregivers and patients during the time $\mathrm{HaH}$

Study design:

Longitudinal cross-

sectional qualitative

study; semi-structured

interviews

Methodology: Not

specified

Analysis: Content

analysis

Study design:

Qualitative study;

Open ended

questionnaires

Methodology: Not

specified

Analysis: Deductive

content analysis

Two categories:

- Potential advantages associated with $\mathrm{HaH}$

- Potential

disadvantage

associated with $\mathrm{HaH}$ health parameters
Six categories:

- Patient-centered care; access

- Communication and

information

- Courtesy and

emotional support

- Technical quality

- Efficiency of care and

organization

- Structure and

facilities 
Table 1. (continued)

\begin{tabular}{|c|c|c|c|c|c|c|}
\hline No. & Study & Country & Aim & Characteristic & Methodology & Results \\
\hline 14 & $\begin{array}{l}\text { Vaartio-Rajalin, Ngoni, \& } \\
\text { Fagerström, } 2019 \\
\text { Balancing between } \\
\text { extremes-Work in } \\
\text { hospital-at-home }\end{array}$ & Finland & $\begin{array}{l}\text { To describe HAH } \\
\text { staff's perceptions } \\
\text { about HAH care, } \\
\text { including work } \\
\text { structures, processes } \\
\text { and outcomes. }\end{array}$ & $\begin{array}{l}\text { Activities of Daily } \\
\text { Living independent } \\
\text { Sample: } 3 \text { focus } \\
\text { group interviews of } \\
\text { interprofessional } \\
\text { staff members } \\
\text { ( } n=24) \\
\text { HaH setting: Early } \\
\text { discharge and } \\
\text { hospital avoidance in } \\
\text { various units (e.g., } \\
\text { COPD, cellulitis, } \\
\text { urinary tract } \\
\text { infections, delirium, } \\
\text { blood monitoring) } \\
\text { Inclusion criteria: } \\
\text { Physicians and } \\
\text { nurses who were } \\
\text { HaH staff }\end{array}$ & $\begin{array}{l}\text { Study design: Cross- } \\
\text { sectional descriptive } \\
\text { study; semi-structured } \\
\text { interview } \\
\text { Methodology: } \\
\text { Inductive } \\
\text { Analysis: Thematic } \\
\text { content analysis }\end{array}$ & $\begin{array}{l}\text { Seven themes } \\
\text { - Staff perceive a } \\
\text { deeper patient-nurse } \\
\text { relationship } \\
\text { - Staff simultaneously } \\
\text { experience } \\
\text { independence and } \\
\text { genuine collaboration } \\
\text { when working in HAH } \\
\text { when compared with } \\
\text { hospital care } \\
\text { - Staff feel motivated } \\
\text { to work } \\
\text { - Staff acknowledge } \\
\text { the effectiveness of } \\
\text { their work } \\
\text { - Staff feel a desire for } \\
\text { professional } \\
\text { self-development } \\
\text { - Staff feel challenged } \\
\text { - Staff feel frustrated }\end{array}$ \\
\hline 15 & $\begin{array}{l}\text { Wang, Haugen, Steihaug, } \\
\& \text { Werner, } 2012 \\
\text { Patients with acute } \\
\text { exacerbation of chronic } \\
\text { obstructive pulmonary } \\
\text { disease feel safe when } \\
\text { treated at home- a quali- } \\
\text { tative study }\end{array}$ & Norway & $\begin{array}{l}\text { To explore patients' } \\
\text { experiences of an } \\
\text { early discharge } \\
\text { hospital at home } \\
\text { (HaH) treatment pro- } \\
\text { gram for exacerba- } \\
\text { tions in COPD. }\end{array}$ & $\begin{array}{l}\text { Sample: } 6 \mathrm{HaH} \\
\text { patients, } 3 \text { hospital } \\
\text { care patients, } 4 \\
\text { spouses } \\
\text { HaH setting: Early } \\
\text { discharge HaH for } \\
\text { COPD patients } \\
\text { Inclusion criteria: } \\
\text { Patients with COPD } \\
\text { needing hospital } \\
\text { admission, and their } \\
\text { spouses were } \\
\text { interviewed }\end{array}$ & $\begin{array}{l}\text { Study design: } \\
\text { Qualitative study; } \\
\text { semi-structured inter- } \\
\text { view } \\
\text { Methodology: Not } \\
\text { specified } \\
\text { Analysis: Kvale's } \\
\text { principles and } \\
\text { retrospective analysis }\end{array}$ & $\begin{array}{l}\text { Results } \\
\text { Despite limited } \\
\text { assistance from the } \\
\text { healthcare service, the } \\
\text { patients and their } \\
\text { spouses experienced } \\
\text { the HaH treatment as } \\
\text { safe. They expressed } \\
\text { that information that } \\
\text { was adapted to specific } \\
\text { situations in their daily } \\
\text { lives and given in a } \\
\text { familiar environment } \\
\text { had positive impact on } \\
\text { their self-management } \\
\text { of COPD. }\end{array}$ \\
\hline 16 & $\begin{array}{l}\text { Wilson, Wynn, \& Parker, } \\
2002 \\
\text { Patient and carer } \\
\text { satisfaction with 'Hospital } \\
\text { at Home': quantitative } \\
\text { and qualitative results } \\
\text { from a randomised } \\
\text { controlled trial }\end{array}$ & UK & $\begin{array}{l}\text { To compare Hospital } \\
\text { at Home patient and } \\
\text { carer satisfaction } \\
\text { with hospital care. }\end{array}$ & $\begin{array}{l}\text { Sample: } 24 \text { patients, } \\
18 \text { carers } \\
\text { HaH setting: HaH } \\
\text { for patients with } \\
\text { cardiovascular or } \\
\text { respiratory diseases } \\
\text { Inclusion criteria: } \\
\text { Patients living alone } \\
\text { or with caregivers } \\
\text { who are not } \\
\text { hospitalized for over } \\
2 \text { weeks in HaH }\end{array}$ & $\begin{array}{l}\text { Study design: Mixed } \\
\text { method; semi- } \\
\text { structured interview } \\
\text { Methodology: Not } \\
\text { specified } \\
\text { Analysis: Thematic } \\
\text { analysis }\end{array}$ & $\begin{array}{l}\text { Four themes: } \\
\text { - Patients appreciated } \\
\text { the more personal care } \\
\text { and better } \\
\text { communication offered } \\
\text { by HaH and placed } \\
\text { great value on staying } \\
\text { at home, which was } \\
\text { seen to be therapeutic } \\
\text { - Patients largely felt } \\
\text { safe in HaH, although } \\
\text { some would have felt } \\
\text { safer in hospital. } \\
\text { - Some patients and } \\
\text { carers felt that better } \\
\text { medical care would } \\
\text { have been provided in } \\
\text { hospital. } \\
\text { - Carers felt that the } \\
\text { workload imposed by } \\
\text { Hospital at Home was } \\
\text { no greater than by } \\
\text { hospital admission and } \\
\text { that the relief from care } \\
\text { duties at home would } \\
\text { be counterbalanced by } \\
\text { the added strain of } \\
\text { hospital visiting }\end{array}$ \\
\hline
\end{tabular}

subthemes by the two independent reviewers (CC and SS). After consensus was reached between the two reviewers, the generated themes and subthemes were comprehensively and concisely distilled into new concepts through meta- synthesis. Triangulation was maintained throughout the synthesis process by constant comparison of individual studies. Regular meetings were held throughout the synthesis process between the reviewers. Triangulation was 
maintained by constant comparison of codes, emerging themes, and the understanding of the participants' views on $\mathrm{HaH}$. Any discrepancies were discussed between the two reviewers until an agreement was made.

\section{RESULTS}

\section{Characteristics of Studies}

A total of 10,469 records were identified, which included 417 additional records from the gray literature. Duplicates were removed using Endnote X9's built-in function, resulting in 6,909 records. From this, 6,284 records were excluded via their title and abstract. The remaining 625 articles underwent a full-text review, which resulted in 16 included articles (Fig. 1). Of the 16 articles, most were in English $(n=15)$ while the one in French was translated to English using Google Translate ${ }^{20}$. The majority of the studies were from America or Europe $(n=15)^{1,12,20-32}$. A third of these studies were based in the UK $(n=5)^{24-27,32}$ and one was in Australia ${ }^{33}$. Studies were qualitative $(n=14)^{1,12,20-24,26-31,33}$, or mixed-methods $(n=2)^{25,32}$. Studies were descriptive $(n=13)^{12,21,23-33}$, utilizing a grounded theory $(n=2)^{1,20}$ or ethnographic approach $(n=1)^{22}$. Most data were collected from individual interviews $(n=12)^{1,21-28,31-33}$, focus group interviews $(n=2)^{20,30}$, or both $(n=1)^{12}$. The remaining study employed open-ended questionnaire ${ }^{29}$. Studies employed thematic analysis $(n=9)^{12,21,22,24-26,30,32,33}$, content analysis $(n=3)^{23,28,29}$, ground theory analysis $(n=2)^{1,20}$, normalizing process theory analysis $(n=1)^{27}$, or retrospective analysis $(n=1)^{31}$. Most HaH provided early discharge $(n=9)^{12,22,25,26,28-31,33}$ compared to admission avoidance $(n=1)^{27}$, while the remaining studies did not specify. The HaH studies included patients who had multiple diagnosis $(n=6)^{1,12,20,23,30,32}$, COPD $(n=3)^{24,29,31}$, cancer $(n=1)^{33}$, renal diseases $(n=1)^{22}$, and mental illnesses $(n=1)^{26}$, and also geriatric $(n=2)^{21,27}$ and orthopedic patients $(n=2)^{25,28}$. All HaH involved multidisciplinary teams or units, and some involved community service providers (e.g., community healthcare practitioners, community nurses, community social care managers, healthcare agency partnerships) $)^{1,12,23,24,27-30,33}$. Table 1 summarizes the studies' characteristics and Table 2 depicts the types of participants interviewed.

Findings were meta-synthesized to form an overarching theme, "the intricacies of developing $\mathrm{HaH}$," pillared by four main themes: (1) factors influencing patient selection, (2) advantages of $\mathrm{HaH}$, (3) challenges of $\mathrm{HaH}$, and (4) enablers for $\mathrm{HaH}$ development (Fig. 2).

\section{Factors Influencing Patient Selection}

This theme consisted of four subthemes to describe the characteristics of patients and caregivers that make them suitable for $\mathrm{HaH}$ : (1) strong social support, (2) positive health behaviors, (3) confidence in receiving care at home, and (4) conducive home environment.
Various studies reported that strong social support assisted patients in home recovery ${ }^{1,24,26,27}$. Social support was mainly provided by caregivers in the form of moral support for the patients ${ }^{1,27}$, ensuring patient safety, and liaising with the healthcare professionals ${ }^{27}$. HaH was reportedly less favorable for patients who did not cohabit with their caregivers ${ }^{27}$ or for patients going through divorces ${ }^{24}$. HaH was found suitable for patients who lived alone and relied on other social connections like "friends" and "neighbors.,"27

$\mathrm{HaH}$ was found to be suitable for patients with positive health behaviors and self-efficacy ${ }^{22,24,25,30}$. This included displaying self-restraint from negative health behaviors (e.g., smoking, drinking, consuming drugs) ${ }^{24,30}$, and self-efficacy in independently performing vital sign monitoring at home ${ }^{22}$. Some studies reported that $\mathrm{HaH}$ was perceived to be less favorable among those who were not confident with remote care and "prefer to be in a cocoon of a hospital environment" with "someone seconds away from them."

Lastly, suitable patients should have a conducive home environment for recovery ${ }^{24,28,30,33}$. Some studies reported difficulty in performing care when patients' pets disrupted administration of intravenous medication ${ }^{30,33}$, the living space was small ${ }^{24}$, or the home environment was unhygienic ${ }^{30}$. Places lacking adaptive home features for safe mobility were also not ideal for home rehabilitation ${ }^{28}$.

\section{Advantages of $\mathrm{HaH}$}

This theme captured the positive experiences of stakeholders with $\mathrm{HaH}$ across different settings. The subthemes were as follows: (1) more comfortable and patient-centered care, (2) perceived better patient clinical outcomes, (3) more family engagement with patients, (4) improved care continuity during and beyond $\mathrm{HaH}$, and (5) increased hospital bed capacity.

$\mathrm{HaH}$ provided patients and caregivers with a more comfortable and personalized hospitalization experience ${ }^{1,20,24,27-30,33}$. All stakeholders from various studies expressed that "being in your own home" helped preserve some sense of normalcy for patients to "follow own daily rhythm,", and "walk around more freely." 24 This reduced anxiety for some and boosted their morale and confidence $e^{1,24,30,33}$. Other studies mentioned that some healthcare professionals and caregivers felt that a sense of normalcy was essential for "end-of-life patients" and their loved ones ${ }^{20,27}$. HaH also removed the need for patients and caregivers to travel to the hospital to receive care or visit their loved ones, respectively ${ }^{24,33}$.

Furthermore, $\mathrm{HaH}$ promoted patient-centered care ${ }^{23,24,27,29-32}$. Patients noted that there was "time to develop rapport" for more "personal and individual" relationships with their healthcare professionals ${ }^{24}$. Similarly, healthcare professionals commented that they had more opportunities to collaborate with their patients ${ }^{23,27}$. Some healthcare professionals noted a power shift between themselves and their patients when there was change in environment (i.e., from ward to home setting). They were no longer just medical staff but were invited as "a guest" at patients" homes with 
their "permission" "30. Since healthcare professionals were able to assess patients in their natural home environment, both parties highlighted that medical advice was more fine-tuned to specific situations in their everyday life ${ }^{29,31}$.

$\mathrm{HaH}$ was perceived to improve clinical outcomes ${ }^{1,24,27,28,30-32}$. Patients reported having improved sleep $^{24,32}$, better appetite ${ }^{1,24,28}$, and speedier recovery ${ }^{24,28}$. From healthcare professionals' perspectives, the familiarity and privacy of home encouraged patients to "reveal something they would never mention while in the hospital" 30,31 that might help tailor better care to their patients.

Patients reported that $\mathrm{HaH}$ allowed them to be closer to their family ${ }^{24,32}$. Recuperating at home was "easier for my family to visit," 24 and couples emphasized the importance of being together at home ${ }^{32}$. Similarly, caregivers agreed that $\mathrm{HaH}$ provided relief to their loved ones who depended heavily on their support ${ }^{32}$.

Some $\mathrm{HaH}$ focused on care continuity during and beyond the intervention itself. For these programs, healthcare professionals noted that they helped to integrate acute care into longterm care management strategies ${ }^{27,30,31}$. Caregivers commented that $\mathrm{HaH}$ was "the best hospital experience because there seems to be aftercare." 27 Healthcare professionals were able to provide patient education that was helpful in the long run, such as advising patients on how to cope with their disease by using their home environment to their advantage ${ }^{31}$, and providing adequate medication reconciliation for them ${ }^{30}$.

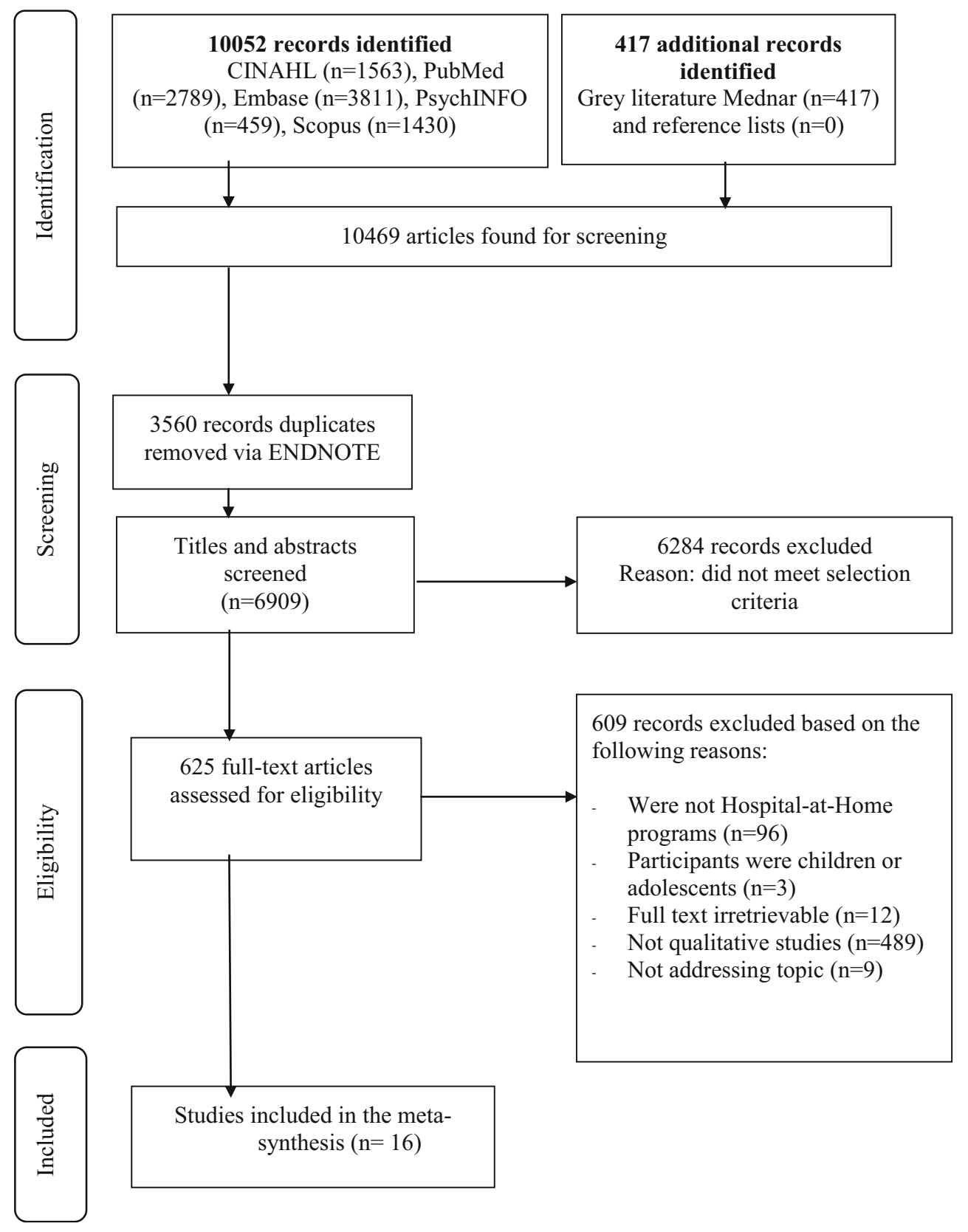

Figure 1 PRISMA flow diagram. 
Table 2 Types of Participants Interviewed in Each Study

\begin{tabular}{|c|c|c|c|c|c|c|c|c|}
\hline$\overline{\text { Study }}$ & Patients & $\begin{array}{l}\text { Caregivers/ } \\
\text { family members }\end{array}$ & Physicians & Nurses & $\begin{array}{l}\text { Social } \\
\text { workers }\end{array}$ & $\begin{array}{l}\text { Allied } \\
\text { health }\end{array}$ & $\begin{array}{l}\text { Clinical/ } \\
\text { healthcare } \\
\text { assistants }\end{array}$ & $\begin{array}{l}\text { Healthcare managers } \\
\text { and administrators }\end{array}$ \\
\hline Brody et al. ${ }^{12}$ & & & $\mathrm{O}$ & $\mathrm{O}$ & $\mathrm{O}$ & & & $\mathrm{O}$ \\
\hline $\begin{array}{l}\text { Buchanan } \\
\text { et al. }\end{array}$ & o & & & & & & & \\
\hline $\begin{array}{l}\text { Cafazzo } \\
\text { et al. }\end{array}$ & o & & & & & & & \\
\hline $\begin{array}{l}\text { Cegarra- } \\
\text { Navarro } \\
\text { et al. }\end{array}$ & & & $\mathrm{o}$ & $\mathrm{o}$ & & & & $\mathrm{o}$ \\
\hline $\begin{array}{l}\text { Cœugnet } \\
\text { et al. }\end{array}$ & & & & o & & & & \\
\hline $\begin{array}{l}\text { Dismore } \\
\text { et al. }\end{array}$ & o & $\mathrm{o}$ & o & o & & & & o \\
\hline Jester $^{25}$ & & o & & & & & & \\
\hline $\begin{array}{l}\text { Khalifeh } \\
\text { et al. }\end{array}$ & $\mathrm{o}$ & o & & & & & & \\
\hline Leung et al. ${ }^{20}$ & & & o & & & & & \\
\hline Mäkelä et al. ${ }^{27}$ & o & o & & & & & & \\
\hline Rossinot et al. ${ }^{1}$ & o & o & & & & & & \\
\hline Sims et al. ${ }^{28}$ & & & $\mathrm{o}$ & $\mathrm{o}$ & & o & o & o \\
\hline Utens et al. ${ }^{29}$ & o & & & & & & & \\
\hline $\begin{array}{l}\text { Vaartio- } \\
\text { Rajalin et al. }{ }^{30}\end{array}$ & & & o & o & & & & \\
\hline Wang et al. ${ }^{31}$ & O & & & & & & & \\
\hline Wilson et al. ${ }^{32}$ & 0 & o & & & & & & \\
\hline
\end{tabular}

Having patients undergoing treatment at home also releases hospital beds to others who need more acute care ${ }^{28}$.

\section{Challenges of $\mathrm{HaH}$}

This theme captured the challenges faced by HaH stakeholders. The subthemes were as follows: (1) lack of round-theclock patient supervision compared to the hospital; (2) increased caregiver burden; (3) unclear and underdeveloped workflows; (4) difficulty in screening, identifying, and recruiting $\mathrm{HaH}$ patients; (5) increased staff burden.

All stakeholders recognized safety as a priority for $\mathrm{HaH}$. Some healthcare professionals and caregivers expressed that HaH lacked the 24-h physical care provided in the hospi$\operatorname{tal}^{27,28}$. This was more prominent for caregivers who did not live with the patients as provision of care was "difficult from a distance." ${ }^{27}$ Remote care also made some patients "rigid with nerves" especially at night when they felt most "alone." This sense of vulnerability was often expressed by COPD

\section{Perceptions of $\mathrm{HaH}$}

\begin{tabular}{|c|c|}
\hline $\begin{array}{l}\text { Theme 1: } \\
\text { Factors } \\
\text { influencing } \\
\text { patient selection }\end{array}$ & $\begin{array}{ll}\text { - } & \text { Strong social support } \\
\text { - } & \text { Positive health behaviors } \\
\text { - } & \text { Confidence in receiving care at home } \\
\text { - } & \text { Conducive home environment }\end{array}$ \\
\hline $\begin{array}{c}\text { Theme 2: } \\
\text { Advantages of } \\
\text { HaH }\end{array}$ & $\begin{array}{ll}\text { - } & \text { More comfortable and patient-centered care } \\
\text { - } & \text { Perceived better patient clinical outcomes } \\
\text { - } & \text { More family engagement with patients } \\
\text { - } & \text { Improved care continuity during and beyond } \mathrm{HaH} \\
\text { - } & \text { Increase hospital bed capacity }\end{array}$ \\
\hline $\begin{array}{c}\text { Theme 3: } \\
\text { Challenges of } \\
\text { НaH }\end{array}$ & $\begin{array}{l}\text { - } \quad \text { Lack of round-the-clock patient supervision compared to the hospital } \\
\text { - } \quad \text { Increased caregiver burden } \\
\text { - } \quad \text { Unclear and underdeveloped workflows } \\
\text { - } \quad \text { Difficulty in screening, identifying and recruiting } \mathrm{HaH} \text { patients } \\
\text { - } \quad \text { Increased staff burden }\end{array}$ \\
\hline $\begin{array}{l}\text { Theme 4: } \\
\text { Enablers for } \\
\text { HaH } \\
\text { development }\end{array}$ & $\begin{array}{ll}\text { - } & \text { Clinicians with strong clinical and communication skills } \\
\text { - } & \text { Importance of maintain quality of care while receiving treatment at home } \\
\text { - } & \text { Supportive operational, regulatory and legal frameworks to promote care delivery in the home setting } \\
\text { Integration with post-discharge care }\end{array}$ \\
\hline
\end{tabular}

Figure 2 Themes and subthemes of the perceptions of $\mathrm{HaH}$. 
patients who were afraid of "being alone at night when I am breathless," 29 or for patients with renal diseases who feared blood loss during home hemodialysis. Lastly, mothers with acute severe mental illnesses from the included studies were mostly overwhelmed with managing distress at home and parenting responsibilities. Hence, they preferred the 24$\mathrm{h}$ care provided in the hospital ${ }^{26}$.

While a few caregivers acknowledged that $\mathrm{HaH}$ freed time "spent in the hospital visiting" to "rest at home,", 32 the transfer of care responsibility from hospital to caregivers was burdensome to some $e^{1,12,24,26-28}$. Those who experienced caregiver burden felt that there was a strong reliance on them to facilitate $\mathrm{HaH}$. They were often tasked with coordinating care, standing by for eventual emergencies, or providing assistance during home treatment. This is especially so for caregivers caring for demented ${ }^{27}$ or mentally ill patients ${ }^{26}$. Caregivers reported the need to help coordinate care between healthcare professionals and the patients as "a multifunction maid." Particularly at night, caregivers were reportedly "sleeping with one eye open" to provide 24-h support ${ }^{27}$ or had their "imagination runs riot" when their confused patients "tried to get out the window," demonstrating difficulties for the family to contain the risk at home for acutely sick patients ${ }^{27}$. Moreover, some caregivers had full-time jobs and household chores ${ }^{1}$. Children of mentally ill patients were reportedly swamped with "emotional responsibilities." Seeing patients sick all the time was a "horrible" or "frightening" experience for others ${ }^{1,24,26}$. Despite the transfer of care responsibility from hospital to caregivers, not all $\mathrm{HaH}$ have in place efforts to recognize caregiver stress, leaving some caregivers burnt out during HaH. Furthermore, the decision for $\mathrm{HaH}$ was often determined by the healthcare professionals and patient's preference, and less influenced by caregivers or family decisions (agreement among several family members).

For many healthcare professionals and administrators, $\mathrm{HaH}$ was operationally challenging. Firstly, since $\mathrm{HaH}$ function beyond the hospital's walls, it was difficult to capture activity within the current payment system ${ }^{24}$, and there was no system in billing patient care as a bundle or single "acute episodes." "12 Absence of a proper billing system created difficulty for organizations to assess cost and cost savings for each case, and deters insurer from covering such services ${ }^{12}$. Secondly, technology was not well integrated into $\mathrm{HaH}$. While proper documentation was important in a multidisciplinary service, some organizations' electronic health records were not nimble enough to sync, record real-time, or integrate among the different care units ${ }^{12,24,30}$. Furthermore, limited studies mentioned the use of remote monitoring system or teleconsultations in $\mathrm{HaH}$. For those which $\operatorname{did}^{22,30}$, the use of a remote monitoring system was physically disruptive to users' daily lives $^{22}$, and teleconsultations yielded "technical problems." 30 Patients requiring complex medical equipment such as home hemodialysis for $\mathrm{HaH}$ also tend to encounter difficulties with the equipment at home. Furthermore, $\mathrm{HaH}$ workflows were sometimes confusing ${ }^{12,20}$. Healthcare professionals were unsure of $\mathrm{HaH}$ entry and exit points, and had problems identifying their clinical roles in $\mathrm{HaH}^{20}$. Healthcare professionals noted that some clinicians lacked certain skills to care for patients at home $e^{12,20,28}$. For example, not all clinicians could perform infusion or had sufficient experience caring for certain groups of patients, which may have hindered access to delivering timely treatment at homes ${ }^{12,28}$.

Screening, identifying, and recruiting suitable $\mathrm{HaH}$ patients were also challenging. Healthcare professionals felt that this process was tedious and time-consuming ${ }^{12,20,30}$. In addition to assessing patients' conditions and their ability to self-care, they had to liaise with caregivers and assess patients' living conditions before enrolment ${ }^{12,20,30}$. Furthermore, recruitment was limited. Although the concept of $\mathrm{HaH}$ is not a novel intervention, some healthcare professionals, patients, and their caregivers have reservations about the implementation of $\mathrm{HaH}$ since acute care is traditionally provided in the hospitals ${ }^{12,24,28}$. The reservations included perceiving the service as a means to "get you out" from the hospital to obtain "empty beds." ${ }^{27,28}$

Some healthcare professionals reported an increase in burden to deliver hospital care to the home ${ }^{1,21,28,30}$. They found the work to be "demanding" as they had to coordinate care, plan their travel time to ensure patients received prompt treatment ${ }^{21,30}$, and adjust to the changing workflows of new $\mathrm{HaH}$ programs $^{30}$. High staff turnover rates were reported ${ }^{1,28}$; organizations that did not address the high turnover rates caused the remaining healthcare professionals to work with "very few sick leave." ${ }^{\prime 30}$

\section{Enablers for HaH Development}

There were four subthemes that characterized enablers of effective HaH: (1) clinicians with strong clinical and communication skills; (2) importance of maintaining quality of care while receiving treatment at home; (3) supportive operational, regulatory, and legal frameworks to promote care delivery in the home setting; and (4) integration with post-discharge care.

Healthcare professionals reported that $\mathrm{HaH}$ team should have strong clinical and communication skills. Firstly, competence in clinical skills is important since they have to make clinical decisions independently ${ }^{30}$. As $\mathrm{HaH}$ relies on remote monitoring, they should also hone their technical skills to operate such technologies ${ }^{23}$. To ensure patients are safe at home, healthcare professionals must be well trained in patient and caregiver selection before $\mathrm{HaH}$ enrolment ${ }^{27}$. Secondly, healthcare professionals need to have effective communication skills to "collaborate" among colleagues, patients, and their family members, and communicate well to "show our respect" in patients' homes ${ }^{30}$. Furthermore, administrators and healthcare professionals reported that teamwork and communication among multiple partners are essential ${ }^{12,20,21,23,28,30}$. For many, HaH was not well integrated to encourage "teamwork or cross-department specialist teams. ${ }^{, 23}$ Timely provision of services and referrals are required to ensure the quality 
of care, that is, no communication delays or missing information, and a robust referral system ${ }^{12,28}$. Studies that reported proper communication among clinicians indicated that the clinicians had better $\mathrm{HaH}$ experiencs ${ }^{12,21,28,30}$.

It is important to maintain quality of care during $\mathrm{HaH}$ as well. This can be provided in the forms of providing assurance, maintaining proper communication, letting patients and their family members be actively engaged in patient recovery ${ }^{24,27,28,30-32}$, communicating treatment predictability ${ }^{32}$, ensuring 24$\mathrm{h}$ telephone services ${ }^{24}$, daily visits ${ }^{24}$, and instilling confidence that help will be promptly given ${ }^{32}$. Patients and caregivers expressed confidence in $\mathrm{HaH}$ when $\mathrm{HaH}$ healthcare professionals were "well trained "and "caring." 31 Furthermore, patients wanted to be engaged in their recovery ${ }^{27,29-31}$ by being involved in their discharge planning ${ }^{27}$, treatment decisions during $\mathrm{HaH}^{27}$, learning more about their medications ${ }^{29}$, and "getting an explanation" on their diagnosis while being at home ${ }^{31}$.

While patient-centeredness care is at the forefront of $\mathrm{HaH}$, the findings revealed that the healthcare system needs to be supported by laws and regulations to maintain staff's safety and medical legal coverage as the care setting shifts to patients' homes $^{12,30}$. Some healthcare professionals revealed that a power shift between them and their patients was observed when provision of care moved from ward to home setting; this was perceived as a challenge for healthcare professionals' safety since they were no longer just medical staff but were "a guest" invited to patients' homes with their "permission.",30

Finally, post-discharge care integration was seen as a priority. Patients and caregivers favored having continuity of care during and beyond $\mathrm{HaH}$. Caregivers wished to know how they could "change the condition" of their loved ones ${ }^{27}$, preferred having reviews by the same specialist ${ }^{29}$, and appreciated follow-ups after $\mathrm{HaH}$ care $^{31}$. Patients and caregivers wanted to be a part of patient recovery and form a continuous relationship with an identified healthcare professional after their $\mathrm{HaH}$ experience ${ }^{27}$.

\section{DISCUSSION}

To our knowledge, this is the first qualitative systematic review that meta-synthesized the perspectives of $\mathrm{HaH}$ stakeholders. We were able to collectively bring together data from multiple disciplines and stakeholders from different countries. Our findings can be categorized into four key points: (1) the need to maintain sustained partnership and personal relationship among patients, caregivers, and healthcare professionals; (2) importance of strengthening communication and collaboration among healthcare professionals; (3) structural change to the traditional care practice; and (4) financial reforms.

Before considering the key points, it is worth noting that $\mathrm{HaH}$ was favorable over hospital setting for majority of the participants with various conditions. However, we found that most patients with conditions that require more acute attention (dementia, mental illness, and COPD) or those requiring complex machineries (home hemodialysis) specifically had more challenges recuperating at home. Future studies could consider providing more healthcare professionals to cater to these patients to improve their $\mathrm{HaH}$ experience.

In general, across all $\mathrm{HaH}$ setting, our findings suggest that maintaining a sustained partnership and personal relationship between patients and healthcare professionals was an enabler of patient satisfaction. Patients reported higher satisfaction when they were included in shared decision-making, received clear communication from managing teams, and were provided patient education specific to their condition during their recovery. This is consistent with other studies which reported that patients' involvement in their own care promoted patient empowerment, created long-term relationship with their healthcare professionals ${ }^{34}$, and increased patient satisfaction $^{34-36}$. Our findings also suggest that patients with designated healthcare providers felt more satisfied than those who had rotating physicians and nurses during their recovery. Maintaining continuous relationship ensured patient-centered care as the same healthcare professionals would have information on the patients' previous clinical history, and an understanding of patients' preferences and needs for a tailored $\mathrm{HaH}$ experience ${ }^{37}$. This is especially so as care is delivered outside the vicinity of the hospital.

Furthermore, there is a need to maintain a sustained partnership between caregivers and healthcare providers. As with the $\mathrm{HaH}$ quantitative studies ${ }^{38,39}$, the caregiver experience varied among included studies. While some caregivers felt less burdened by $\mathrm{HaH}$ compared to the hospital setting, more were stressed from the transferred responsibility of care from hospital to home. Surprisingly, most $\mathrm{HaH}$ did not have in place efforts to recognize and mitigate caregiver stress. Despite caregivers playing large roles in $\mathrm{HaH}$, the decision for $\mathrm{HaH}$ was often determined by healthcare professionals and patients' preferences, and less influenced by them or other family members. Care decision which considered caregiver's and other family members' decisions resulted in higher caregiver satisfaction ${ }^{40}$. Another study reported that the likelihood of caregiver burden was the determining factor for patients' decision on choosing either hospital or home care ${ }^{41}$. Given that caregiver burden remains a significant concern, family decisions and caregivers' preferences should be considered when evaluating patients for $\mathrm{HaH}$. When an agreement is made for $\mathrm{HaH}$, there should be substantial efforts to ensure that caregivers are well supported during this process. Adoption of continuous remote vital signs monitoring technology to monitor patient safety and 24/7 access to healthcare providers may help to mitigate fear and anxiety, and provide support for caregivers ${ }^{42}$. Providing measures to alleviate caregiver burden can help ensure better partnership with healthcare professionals and improve patient care at home.

Secondly, communication and collaboration among healthcare professionals are essential in ensuring continuity of care, which is especially important as care shifts from hospital to home ${ }^{43}$. The use of technology is integral to facilitate communication and collaboration in the community setting, and ensure timely 
detection of complications at home ${ }^{44}$. As reported in the included studies, inter-professional collaboration, coordination, and communication were challenges commonly cited and many studies did not mention any integration of technology for HaH. Studies that integrated technology faced difficulties in syncing $\mathrm{HaH}$ patient records into electronic health records ${ }^{12,24}$, the lack of user-friendly remote vital signs monitoring ${ }^{22}$, and technical problems with virtual physician visits ${ }^{30}$. These findings corroborate findings from other studies where technologies assisting care at home are still not optimal ${ }^{45}$. Hence, organizations need to improve technological advancement through policies that enable access to medical records across inter-departments or develop shared access to electronic health records that would allow ease of communication and collaboration among healthcare professionals, patients, and their family members ${ }^{46,47}$. Future $\mathrm{HaH}$ should also consider incorporating and evaluating the effectiveness of remote vital signs monitoring and virtual physician visits to improve technology integration in $\mathrm{HaH}$. Strong communication and collaboration are the building blocks for improving access to care in the community setting ${ }^{44}$, and better integration of technological advancements can help greatly in this aspect ${ }^{48}$.

Thirdly, as care shifts to home, there is a need for structural changes to the traditional care practice, and a need to reorganize care delivery ${ }^{44}$. However, as noted from the included studies, the structural changes were challenging. Some highlighted that the $\mathrm{HaH}$ team lacked in skills and were uncertain of their roles and responsibilities in $\mathrm{HaH}$. This may have been contributed by the heterogeneity of $\mathrm{HaH}$ which admits a broad range of patients with orthopedic conditions to urinary tract infection, thus making it challenging for patients to be matched with the right healthcare professionals ${ }^{49}$. HaH which engaged with community care services (e.g., general practitioners and community nurses) observed that some healthcare professionals did not have the skills to care for acute patients. Hence, substantial clinical training is required to ensure that healthcare professionals are fully equipped to manage acute patient care at home, and policies which ensure clear roles and responsibilities have to be developed ${ }^{23,50}$. The demands and challenges of structural changes may have resulted in high staff turnover rates as reported in some included studies; this disrupted HaH workflow and affected patients' continuity of $\operatorname{care}^{28}$. Policy reforms are needed to ensure that ethical and legal standards in $\mathrm{HaH}$ care are clear ${ }^{51}$ and that there are measures in place to ensure healthcare professionals are protected outside of the hospital environment. ${ }^{52}$. This can be further mitigated by having recruitment and retention practices that can minimize burnout and reduce staff turnover rate ${ }^{53}$.

Lastly, payment models and payment system are not well established in $\mathrm{HaH}^{54}$ and vary between settings and countries. Many such schemes lack robust payment models that capture activity within the payment system and there are barriers to create a single unified billing and payment mechanism. The recent announcement by the Center for Medicare and Medicaid Services, which provides broad regulatory flexibility for $\mathrm{HaH}$ due to the COVID-19 pandemic, is a great enabler for $\mathrm{HaH}$ in the $\mathrm{USA}^{55}$. Such regulatory and healthcare financing reforms $^{56}$ are critical for any healthcare system to comprehensively develop $\mathrm{HaH}^{57}$

\section{LIMITATIONS OF REVIEW}

This qualitative system review has a few limitations. Firstly, majority of the articles included in this review were mainly from Western regions (Europe, the USA, and Australia) with robust healthcare systems. Hence, findings may not be representative of those in other countries and cultures. Secondly, this qualitative review heterogeneously examined a diverse set of stakeholders' perspectives (e.g., healthcare professionals, administrators, patients, and caregivers) of $\mathrm{HaH}$ in different contexts (e.g., cancer, cardiovascular, or orthopedic units) that may not represent discipline- or disease-specific needs of the stakeholders. Thirdly, most $\mathrm{HaH}$ models were early discharge or unspecified, with limited studies evaluating the effectiveness of admission avoidance.

\section{IMPLICATIONS FOR FUTURE RESEARCH AND PRACTICE}

Our findings on the key enablers and challenges of HaH may help to improve $\mathrm{HaH}$.

This review included $\mathrm{HaH}$ treating a variety of patient conditions. While $\mathrm{HaH}$ is favorable over hospital setting for the majority of participants with various conditions, we found that most patients with conditions that required more acute attention (e.g., those with dementia, mental illness, or COPD), or those requiring complex care (e.g., home hemodialysis), had more challenges recuperating at home. Future studies can consider more interventions to improve $\mathrm{HaH}$ experiences for such patients.

Overall, $\mathrm{HaH}$ practice varied based on availability of resources in each country as well as ethnicity, beliefs, and family culture. Future research could explore whether views toward $\mathrm{HaH}$ differ in different cultural contexts (e.g., Asian cultures, multiracial populations) availability of resources (e.g., lower- and middle-income counties), and $\mathrm{HaH}$ models (e.g., early discharge versus admission avoidance).

Forging partnership and personal relationship between patient and healthcare professionals is important in $\mathrm{HaH}$. To improve patient satisfaction, these programs should continue to focus on patient-centeredness and individualization of care. This can be achieved through shared decision-making, clear communication from managing teams, and provision of specific patient education based on each patient's condition during their recovery. To maintain partnership with caregivers, healthcare professionals should include both caregivers and family 
members rather than just the patient in the decision process. Considering the heavy reliance on caregivers, there should also be strategies to mitigate caregiver burnout.

There should be recruitment and retention measures to support healthcare professionals to minimize burnout and high staff turnover rate. Measures should be in place to reduce the risk of medico-legal matters and ensure both healthcare professionals and patients are protected throughout the $\mathrm{HaH}$ journey.

From a policy standpoint, further technological integration and advancement are essential to allow collaboration among healthcare providers to facilitate care at home. Finally, payment reforms are needed to adequately include $\mathrm{HaH}$ for reimbursement and insurance coverage.

\section{CONCLUSION}

In this review, we gained a deeper understanding of the $\mathrm{HaH}$ experience of different stakeholders. This review highlighted patient-centeredness as the key benefit of such programs and highlighted key operational and policy considerations in developing and improving $\mathrm{HaH}$. Considering these factors, the intentional shift of acute care from hospital to home could address modern healthcare challenges of rising healthcare cost and limited hospital capacity, especially in the face of the ongoing COVID-19 pandemic.

Acknowledgements: A Ministry of Health Office for Healthcare Transformation (MOHT) employee was involved in the review as a research collaborator. He provided input in the design of the review as well as the writing of this paper in his capacity as an associate with Alexandra Hospital, National University Health System, Singapore.

Corresponding Author: Shefaly Shorey, PhD, RN, RM; Alice Lee Centre for Nursing Studies, Yong Loo Lin School of Medicine, National University of Singapore, Singapore, Singapore (e-mail: nurssh@nus. edu.sg).

Supplementary Information The online version contains supplementary material available at https://doi.org/10.1007/s11606-02107065-0.

Funding This research was funded by the MOHT to support the prepilot research for Hospital-at-Home Program in the National University Health System in Singapore. The funder declared no commercial interest in this review and played no role in the design, analysis, interpretation of this qualitative data, or the writing of this paper.

\section{Declarations:}

Conflict of Interest: The authors declare that they do not have a conflict of interest.

\section{REFERENCES}

1. Rossinot H, Marquestaut O, de Stampa M. The experience of patients and family caregivers during hospital-at-home in France. BMC health services research. 2019;19(1):470-470. doi: https://doi.org/10.1186/ s12913-019-4295-7.
2. Cryer L, Shannon SB, Amsterdam Mv, Leff B. Costs For 'Hospital At Home' Patients Were 19 Percent Lower, With Equal Or Better Outcomes Compared To Similar Inpatients. Health affairs (Millwood, Va). 2012;31(6):1237. https://doi.org/10.1377/hlthaff.2011.1132.

3. Leong MQ, Lim CW, Lai YF. Comparison of Hospital-at-Home models: a systematic review of reviews. BMJ open. 2021;11(1):e043285-e043285. doi: https://doi.org/10.1136/bmjopen-2020-043285.

4. Pericàs JM, Cucchiari D, Torrallardona-Murphy O, et al. Hospital at home for the management of COVID-19: preliminary experience with 63 patients. 2020. doi: https://doi.org/10.1007/s15010-020-01527-z.

5. Pericàs JM, Cucchiari D, Torrallardona-Murphy O, et al. Hospital at home for the management of COVID-19: preliminary experience with 63 patients. Infection. 2020:1-6. doi: https://doi.org/10.1007/s15010-02001527-z.

6. Heller DJ, Ornstein KA, DeCherrie LV, et al. Adapting a Hospital-atHome Care Model to Respond to New York City's COVID-19 Crisis. Journal of the American Geriatrics Society (JAGS). 2020;68(9):1915-1916. doi: https://doi.org/10.1111/jgs.16725.

7. Gaddoura A, Yazdan-Ashoori P, Kabali C, et al. Efficacy of Hospital at Home in Patients with Heart Failure: A Systematic Review and MetaAnalysis. PloS one. 2015;10(6):e0129282-e0129282. doi: https://doi. org/10.1371/journal.pone.0129282.

8. Shepperd S, Gonçalves-Bradley DC, Straus SE, Wee B. Hospital at home: home-based end-of-life care. Cochrane library. 2016;2016(2):CD009231-CD009231. doi: https://doi.org/10.1002/ 14651858.cd009231.pub2.

9. Gonçalves-Bradley DC, nliffe S, Doll HA, et al. Early discharge hospital at home. Cochrane library. 2017;2017(6):CD000356-CD000356. doi: https://doi.org/10.1002/14651858.CD000356.pub4.

10. Levine DM, Ouchi K, Blanchfield B, et al. Hospital-Level Care at Home for Acutely Ill Adults: A Randomized Controlled Trial. Annals of internal medicine. 2020;172(2):77-85. doi: https://doi.org/10.7326/M19-0600.

11. Hensher M, Fulop N, Hood S, Ujah S. Does hospital-at-home make economic sense ? Early discharge versus standard care for orthopaedic patients. Journal of the Royal Society of Medicine. 1996;89(10):548-551. doi: https://doi.org/10.1177/014107689608901003.

12. Brody AA, Arbaje AI, DeCherrie LV, Federman AD, Leff B, Siu AL Starting Up a Hospital at Home Program: Facilitators and Barriers to Implementation. Journal of the American Geriatrics Society (JAGS). 2019;67(3):588-595. doi: https://doi.org/10.1111/jgs. 15782.

13. Morano B, Jimenez-Mejia J, Sanon M, Morano C, DeCherrie LV. Acute Care in the Home Setting: Hospital at Home. Cham: Springer International Publishing; 2019:393-401.

14. Sandelowski M, Barroso J. Classifying the Findings in Qualitative Studies. Qualitative health research. 2016;13(7):905-923. doi: https:// doi.org/10.1177/1049732303253488.

15. Moher D, Liberati A, Tetzlaff J, Altman DG, Group P, for the PG. Preferred reporting items for systematic reviews and meta-analyses: the PRISMA statement. BMJ. 2009;339(7716):332-336. doi: https://doi.org/ 10.1136/bmj.b2535.

16. Cahill M, Robinson K, Pettigrew J, Galvin R, Stanley M. Qualitative synthesis: A guide to conducting a meta-ethnography. Vol 81. London, England: SAGE Publications; 2018:129-137. https://doi.org/10.1177/ 0308022617745016.

17. Hannes K, Lockwood C, Pearson A. A Comparative Analysis of Three Online Appraisal Instruments' Ability to Assess Validity in Qualitative Research. Qualitative health research. 2010;20(12):1736-1743. doi: https://doi.org/10.1177/1049732310378656.

18. Nadelson S, Nadelson LS. Evidence-Based Practice Article Reviews Using CASP Tools: A Method for Teaching EBP. Worldviews on evidence-based nursing. 2014; 11(5):344-346. doi: https://doi.org/10.1111/wvn. 12059.

19. Butler A, Hall H, Copnell B. A Guide to Writing a Qualitative Systematic Review Protocol to Enhance Evidence-Based Practice in Nursing and Health Care. Worldviews on evidence-based nursing. 2016;13(3):241-249. doi: https://doi.org/10.1111/wvn.12134.

20. Leung I, Casalino E, Pateron D, Grateau G, Garandeau E, de Stampa M. Participation of general practitioners in the management of their "hospital at home" patients. Santé publique (Vandoeuvre-lès-Nancy, France). 2016;28(4):499-504. https://doi.org/10.3917/spub.164.0499.

21. Cœugnet S, Forrierre J, Naveteur J, Dubreucq C, Anceaux F. Time pressure and regulations on hospital-in-the-home (HITH) nurses: An onthe-road study. Applied Ergonomics. 2016;54:110-119. doi: https://doi. org/10.1016/j.apergo.2015.11.018.

22. Cafazzo JA, Leonard K, Easty AC, Rossos PG, Chan CT. The usercentered approach in the development of a complex hospital-at home 
intervention. Studies in health technology and informatics. 2009;143:328333. doi: https://doi.org/10.3233/978-1-58603-979-0-328.

23. Cegarra-Navarro J-G, Wensley AKP, Sánchez-Polo M-T. An Application of the Hospital-in-the-Home Unlearning Context. Social work in health care. 2010;49(10):895-918. doi: https://doi.org/10.1080/00981389. 2010.506410 .

24. Dismore L, Echevarria C, Van-Wersch A, Simpson AJ, Gibson GJ, Bourke SC. P213 Positive drivers and potential barriers to implementation of hospital at home selected by low risk decaf score. Thorax. 2016;71(Suppl 3):A201-A201. doi: https://doi.org/10.1136/thoraxjnl2016-209333.356.

25. Jester R. Early discharge to hospital at home: should it be a matter of choice? Journal of orthopaedic nursing. 2003;7(2):64-69. doi: https://doi. org/10.1016/S1361-3111(03)00003-7.

26. Khalifeh H, Murgatroyd C, Freeman M, Johnson S, Killaspy H. Home Treatment as an Alternative to Hospital Admission for Mothers in a Mental Health Crisis: A Qualitative Study. Psychiatric Services. 2009;60(5):634-639. doi: https://doi.org/10.1176/ps.2009.60.5.634

27. Mäkelä $\mathbf{P}$, Stott $\mathbf{D}$, Godfrey $\mathbf{M}$, Ellis G, Schiff R, Shepperd S. The work of older people and their informal caregivers in managing an acute health event in a hospital at home or hospital inpatient setting. Age and ageing. 2020;49(5):856-864. doi: https://doi.org/10.1093/ageing/afaa085.

28. Sims J, Rink E, Walker R, Pickard $\mathbf{L}$. The introduction of a hospital at home service: A staff perspective. Journal of interprofessional care. 1997;11(2):217-224. doi: https://doi.org/10.3109/ 13561829709014913.

29. Utens CMA, Goossens LMA, van Schayck OCP, et al. Patient preference and satisfaction in hospital-at-home and usual hospital care for COPD exacerbations: Results of a randomised controlled trial. International journal of nursing studies. 2013;50(11):1537-1549. doi: https://doi.org/ 10.1016/j.ijnurstu.2013.03.006.

30. Vaartio-Rajalin H, Ngoni K, Fagerström L. Balancing between extremes-Work in hospital-at-home. Nursing open. 2019;7(1):398-410. doi: https://doi.org/10.1002/nop2.402.

31. Wang $\mathbf{Y}$, Haugen $\mathbf{T}$, Steihaug $\mathbf{S}$, Werner A. Patients with acute exacerbation of chronic obstructive pulmonary disease feel safe when treated at home: a qualitative study. BMC pulmonary medicine. 2012;12(1):45-45. doi: https://doi.org/10.1186/1471-2466-12-45.

32. Wilson A, Wynn A, Parker H. Patient and carer satisfaction with 'hospital at home': quantitative and qualitative results from a randomised controlled trial. British Journal of General Practice. 2002;52(474):9-13.

33. Buchanan L, Clarke JL, Sulkowski AJ, et al. There's no place like home: a prospective evaluation of chemotherapy in the home. The Australian journal of cancer nursing. 2003;4(1): 18 .

34. Vaartio-Rajalin H, Fagerström L. Professional care at home: Patientcentredness, interprofessionality and effectivity? A scoping review. Health \& social care in the community. 2019;27(4):e270-e288. doi: https://doi. org/10.1111/hsc. 12731 .

35. McMillan SS, Kendall E, Sav A, et al. Patient-Centered Approaches to Health Care: A Systematic Review of Randomized Controlled Trials. Medical care research and review. 2013;70(6):567-596. doi: https://doi. org/10.1177/1077558713496318.

36. Mercer SW, Neumann M, Wirtz M, Fitzpatrick B, Vojt G. General practitioner empathy, patient enablement, and patient-reported outcomes in primary care in an area of high socio-economic deprivation in Scotland-A pilot prospective study using structural equation modeling. Patient education and counseling. 2008;73(2):240-245. doi: https://doi. org/10.1016/j.pec.2008.07.022.

37. Chen LM, Ayanian JZ. Care Continuity and Care Coordination: What Counts? JAMA internal medicine. 2014;174(5):749-750. doi: https://doi. org/10.1001/jamainternmed.2013.14331.

38. Leff B, Burton L, Mader SL, et al. Comparison of Stress Experienced by Family Members of Patients Treated in Hospital at Home with That of Those Receiving Traditional Acute Hospital Care. Journal of the American Geriatrics Society (JAGS). 2008;56(1):117-123. doi: https://doi.org/10. 1111/j.1532-5415.2007.01459.x.

39. Lippert M, Semmens S, Tacey $\mathbf{L}$, et al. The Hospital at Home program: no place like home. Current oncology (Toronto). 2017;24(1):23-27. doi: https://doi.org/10.3747/co.24.3326.

40. Marcén M, Molina JA. Informal caring-time and caregiver satisfaction. The European journal of health economics. 2012;13(6):683-705. doi: https://doi.org/10.1007/s10198-011-0322-2.
41. Goossens LMAP, Utens CMAP, Smeenk FWJMPMD, Donkers BP, van Schayck OCPP, Rutten-van Mölken MPMHP. Should I Stay or Should I Go Home? A Latent Class Analysis of a Discrete Choice Experiment on Hospital-At-Home. Value in health. 2014;17(5):588-596. doi: https://doi. org/10.1016/j.jval.2014.05.004.

42. Haranath SP, Udayasankaran JG. Tele-intensive care unit networks: A viable means for augmenting critical care capacity in India for the COVID pandemic and beyond. Apollo Medicine. 2020;17(3):209. doi: https://doi. org/10.4103/am.am_104_20.

43. Rezapour-Nasrabad $\mathbf{R}$. Transitional care model: managing the experience of hospital at home. Electronic journal of general medicine. 2018;15(5). https://doi.org/10.29333/ejgm/93445.

44. Jackson GL, Powers BJ, Gray R, et al. The Patient-Centered Medical Home: A Systematic Review. Annals of internal medicine. 2013;158(3):169-178. doi: https://doi.org/10.7326/0003-4819-158-3201302050-00579.

45. Leenen JPL, Leerentveld C, van Dijk JD, van Westreenen HL, Schoonhoven L, Patijn GA. Current Evidence for Continuous Vital Signs Monitoring by Wearable Wireless Devices in Hospitalized Adults: Systematic Review. Journal of medical Internet research. 2020;22(6):e18636-e18636. doi: https://doi.org/10.2196/18636.

46. O'Malley AS, Grossman JM, Cohen GR, Kemper NM, Pham HH. Are Electronic Medical Records Helpful for Care Coordination? Experiences of Physician Practices. Journal of general internal medicine : JGIM. 2009;25(3): 177-185. doi: https://doi.org/10.1007/s11606-009-1195-2.

47. Saunders S, Killackey T, Kurahashi A, et al. Palliative Care Transitions From Acute Care to Community-Based Care-A Systematic Review. Journal of pain and symptom management. 2019;58(4):721-734.e721. doi: https://doi.org/10.1016/j.jpainsymman.2019.06.005.

48. Øvretveit J. Digital Technologies Supporting Person-Centered Integrated Care - A Perspective. International journal of integrated care. 2017;17(4):6-6. doi: https://doi.org/10.5334/ijic.3051.

49. Shepperd S, Iliffe S. Hospital at home versus in-patient hospital care. Cochrane database of systematic reviews 2005(3):CD000356-CD000356.

50. Cuxart Mèlich A, Estrada Cuxart O. Hospital at home: an opportunity for change. Medicina clinica. 2012;138(8):355-360. doi: https://doi.org/ 10.1016/j.medcli.2011.04.008.

51. Mogensen CB, Ankersen ES, Lindberg MJ, et al. Admission rates in a general practitioner-based versus a hospital specialist based, hospital-athome model: ACCESS, an open-labelled randomised clinical trial of effectiveness. Scandinavian journal of trauma, resuscitation and emergency medicine. 2018;26(1):26-26. doi: https://doi.org/10.1186/s13049018-0492-3

52. Rosenthal LJ, Byerly A, Taylor AD, Martinovich Z. Impact and Prevalence of Physical and Verbal Violence Toward Healthcare Workers. Psychosomatics (Washington, DC). 2018;59(6):584-590. doi: https://doi. org/10.1016/j.psym.2018.04.007.

53. Nowrouzi $\mathbf{B}$, Lightfoot $\mathbf{N}$, Larivière $\mathbf{M}$, et al. Occupational Stress Management and Burnout Interventions in Nursing and Their Implications for Healthy Work Environments: A Literature Review. Workplace health \& safety. 2015;63(7):308-315. doi: https://doi.org/10.1177/ 2165079915576931.

54. Cheng $\mathbf{J}$, Montalto $\mathbf{M}$, Leff $\mathbf{B}$. Hospital at home. Clinics in geriatric medicine. 2009;25(1):79-91. doi: https://doi.org/10.1016/j.cger.2008. 10.002 .

55. Centers for Medicare \& Medicaid Services. CMS Announces Comprehensive Strategy to Enhance Hospital Capacity Amid COVID-19 Surge. 2020. https://www.cms.gov/newsroom/press-releases/cms-announces-comprehensive-strategy-enhance-hospital-capacity-amid-covid-19-surge. Accessed 15 Feb 2021

56. Nielsen M, Buelt L, Patel $\mathbf{K}$, Nichols LM, Fund MM. The patientcentered medical home's impact on cost and quality. Annual review of evidence. 2014;2015:202014-202015.

57. Rodriguez Verjan C, Augusto V, Xie X, Buthion V. Economic comparison between Hospital at Home and traditional hospitalization using a simulation-based approach. Journal of enterprise information management. 2013;26(1/2):135-153. doi: https://doi.org/10.1108/ 17410391311289596.

Publisher's Note: Springer Nature remains neutral with regard to jurisdictional claims in published maps and institutional affiliations. 